\title{
Human Carbonic Anhydrase III: Structural and Kinetic Study of Catalysis and Proton Transfer.
}

David M. Duda, Chingkuang Tu, Zoë Fisher, Haiqain An, Craig Yoshioka, Lakshmanan Govindasamy, Philip J. Laipis, Mavis Agbandje-McKenna, David N. Silverman, Robert McKenna

\section{Supporting Information}

S 1: Active site distance geometry ( $\AA$ ) of HCA III, F198L HCA III, RCA III, and HCA II.

\begin{tabular}{|c|c|c|c|c|}
\hline & HCA III & F198L HCA III & RCA III $^{\mathbf{a}}$ & HCA II $^{\mathbf{b}}$ \\
\hline $\mathrm{Zn}^{2+}-\mathrm{OH}^{-} / \mathrm{H}_{2} \mathrm{O}$ & 2.0 & 2.0 & 1.9 & 1.9 \\
\hline $\mathrm{Zn}^{2+} \mathrm{OH}^{-} / \mathrm{H}_{2} \mathrm{O}-\mathrm{W} 1^{\mathrm{c}}$ & 2.8 & 2.8 & 2.7 & 2.9 \\
\hline $\mathrm{W} 1-\mathrm{W}{ }^{\mathrm{c}}$ & 3.0 & 2.9 & 3.0 & 2.9 \\
\hline $\mathrm{Zn}^{2+} \mathrm{OH}^{-} / \mathrm{H}_{2} \mathrm{O}-\mathrm{O} \gamma 1 \mathrm{~T} 199$ & 2.5 & 2.8 & 2.6 & 2.5 \\
\hline $\mathrm{W}^{\mathrm{c}}-\mathrm{O} \gamma 1 \mathrm{~T} 200$ & 2.4 & 2.7 & 2.8 & 2.9 \\
\hline $\mathrm{Wd}^{\mathrm{c}}-\mathrm{O} \mathrm{T} 199$ & 2.7 & 2.8 & 2.8 & 7.3 \\
\hline$\left(\right.$ Phe or Leu)198 $\mathrm{C}_{\alpha}-\mathrm{Zn}^{2+}$ & 6.7 & 6.9 & 6.9 & 8.5 \\
\hline (Phe or Leu)198 C $-\mathrm{Zn}^{2+}$ & 7.1 & 7.8 & 7.3 & \\
\hline
\end{tabular}

${ }^{\mathrm{a}}$ From Ref. 14 (PDB accession number 1FlJ).

${ }^{\mathrm{b}}$ From Ref. 36.

${ }^{\mathrm{c}} \mathrm{W} 1, \mathrm{~W} 2$, and Wd refer to the solvent molecules labeled in Figure 2. 
S 2: Two-dimensional representation of the interactions observed between the hexahistidine tag in the active site of A) HCA III and B) F198L HCA III. The half spheres in red indicate residues that are involved in hydrophobic contacts and those shown as ball-and-stick are within hydrogen bond distances (2.6-3.2 A) depicted as green dashed lines with the hexahistidine tag. All residues are as labeled.

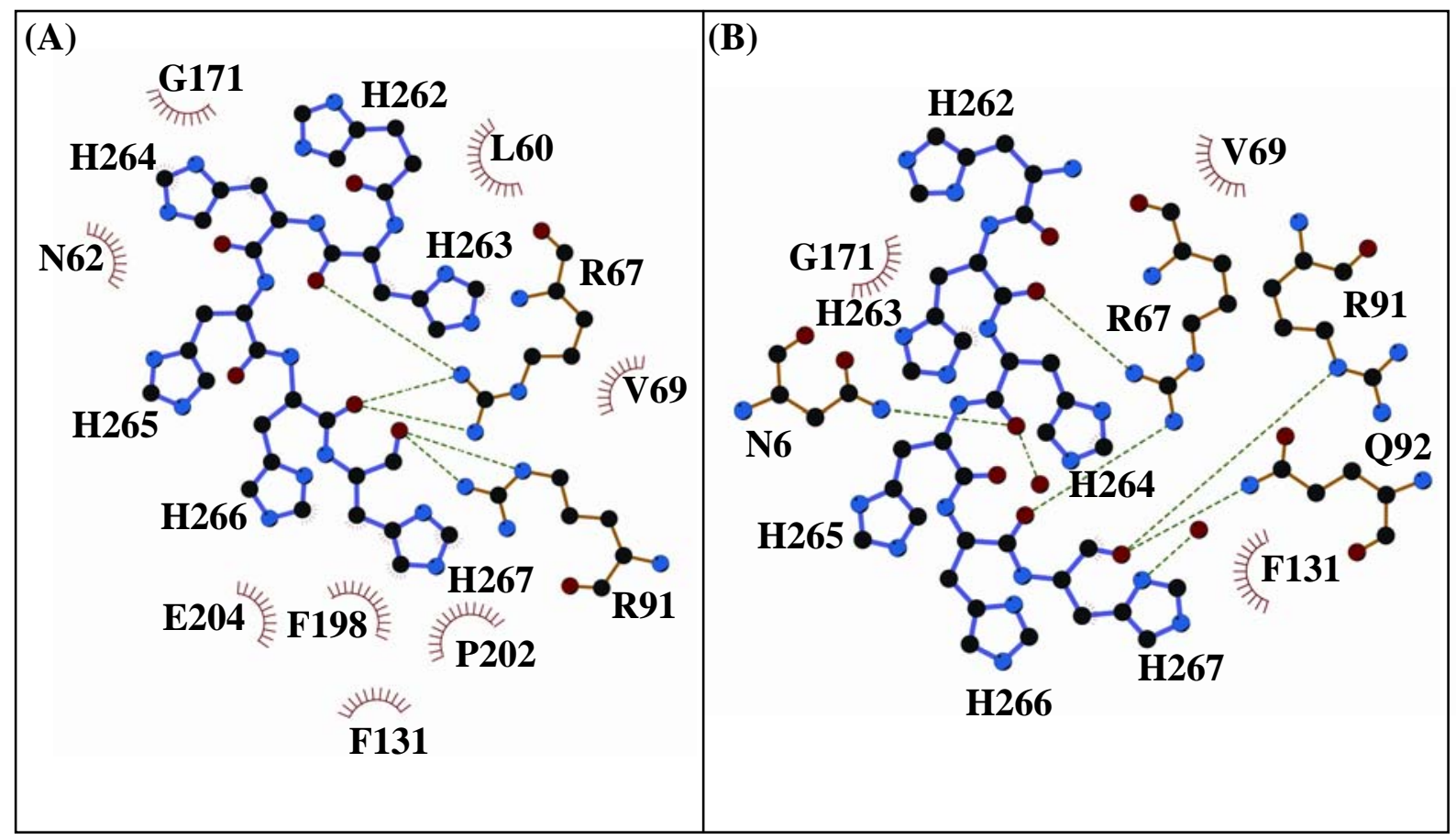


S3 . Active sites of (A) HCA III and (B) F198L HCA III. Solvent molecules are shown as red spheres and inferred hydrogen bonds as dashed red lines. The zinc bound hydroxide/water, and solvent W1, W2, and Wd are labeled. Note the hydrogen bond between W5 and K64 (red arrow) in (A).
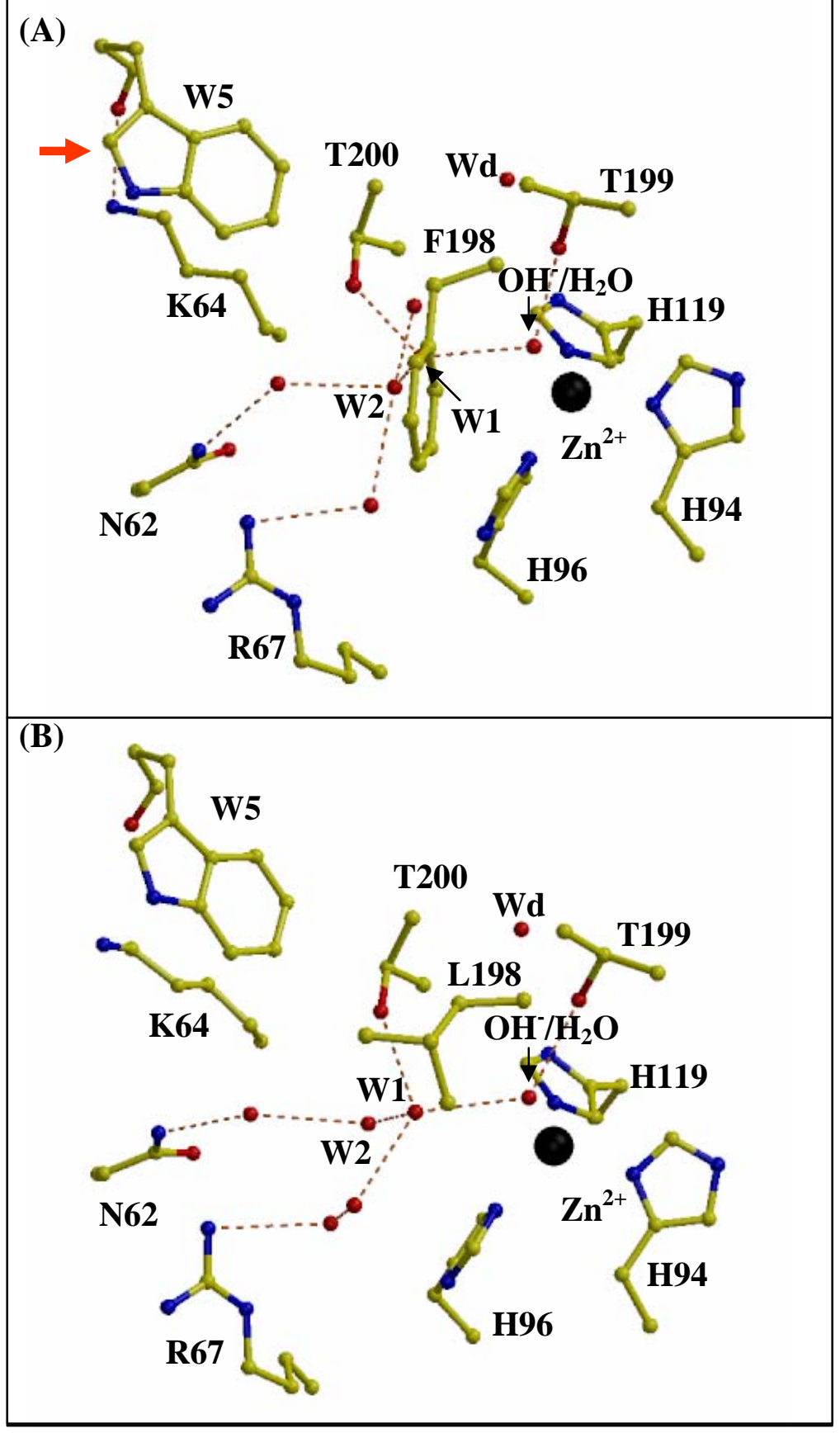